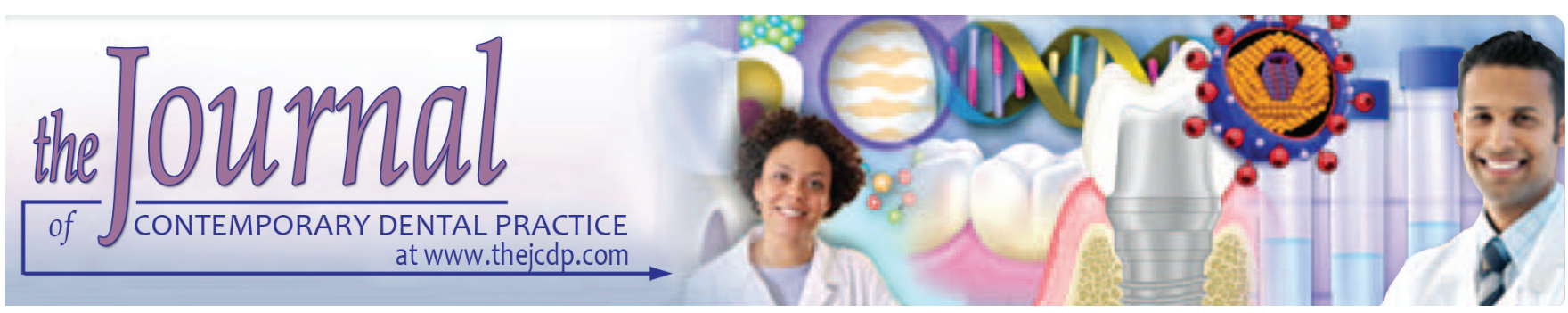

\title{
Osteoporosis Knowledge and Related Health Behavior among Women in Jazan Region, Kingdom of Saudi Arabia
}

${ }^{1}$ Ismail A Darout, ${ }^{2}$ Abdulwahab Alamir, ${ }^{3}$ Sameena Sultana

\begin{abstract}
Introduction: Osteoporosis is a systemic bone disease that can be prevented to some extent by awareness of its risk factors and related health behavior. The aim of this study was to collect information about knowledge and awareness of osteoporosis among women living in Jazan and to describe the type of food habits, sociodemographic characteristics, and other osteoporosis-related health behavior.
\end{abstract}

Materials and methods: Self-administered questionnaires were used for data collection. The total participants were 546 women: 88 (16.1\%) were health professionals and $458(83.9 \%)$ non health professionals in the age range $\leq 20$ to 50 years. Data collection was facilitated by a trained intern female doctor of dentistry whose task was to administer the distribution and collection of the questionnaires.

Results: In total, $61.9 \%$ of health professionals and $54.3 \%$ of nonhealth professionals scored highly on knowledge of osteoporosis. The respondents of osteoporosis preventive food items were also highly knowledgeable with 50.6 and $52.6 \%$ of health and nonhealth professionals respectively. About $48.1 \%$ of health professional and $44.2 \%$ of nonhealth professional scored low on knowledge of osteoporosis behavior and attitude, vitamin supplements, and sunlight exposure. The age effect on osteoporosis knowledge was $33.8 \%$ in young age group and $30.7 \%$ in old age group.

Conclusion: Our study shows that Jazan women were highly knowledgeable and aware about osteoporosis and its related health behavior and that health professionals and nonhealth professionals were equally aware about osteoporosis-related health matters.

\footnotetext{
${ }^{1,3}$ Department of Preventive Dental Sciences, Division of Periodontics, College of Dentistry, Jazan University, Jazan Kingdom of Saudi Arabia

${ }^{2}$ Department of Oral and Maxillofacial Surgery and Diagnostic Sciences, College of Dentistry, Jazan University, Jazan Kingdom of Saudi Arabia

Corresponding Author: Ismail A Darout, Department of Preventive Dental Sciences, Division of Periodontics, College of Dentistry, Jazan University, Jazan, Kingdom of Saudi Arabia e-mail: idarout1959@gmail.com
}

Clinical significance: Awareness and preventive behavior of osteoporosis can prevent or slow the development of the disease.

Keywords: Awareness, Health-related behavior, Knowledge, Osteoporosis, Women.

How to cite this article: Darout IA, Alamir A, Sultana S. Osteoporosis Knowledge and Related Health Behavior among Women in Jazan Region, Kingdom of Saudi Arabia. J Contemp Dent Pract 2017;18(5):378-382.

Source of support: Nil

Conflict of interest: None

\section{INTRODUCTION}

Osteoporosis is a systemic bone disease that affects bone mass and leads to increase in bone fragility and fracture. It is the main cause of mortality and morbidity of the elderly population. ${ }^{1}$ The prevalence of osteoporosis is high in the developed nations, especially among women in increasing age. Osteoporosis has been ranked as the second disease after heart diseases for public health concern. ${ }^{2}$ Worldwide, one-third of women with age range from 60 to 70 years and about two-thirds of 80-year-olds complain from osteoporosis. ${ }^{3}$ Evidence showed that periodontal disease and osteoporosis are bone resorptive diseases that affect a large number of people, in particular, with old ages. ${ }^{4}$

It is suggested that osteoporosis affects periodontal disease and that both diseases shared their progression with advancing age. ${ }^{5-7}$ Studies have shown that 13 to $18 \%$ of women 50 years old had osteoporosis and that this proportion increased up to $70 \%$ for women over 80 years of age. ${ }^{8,9}$ Thus, in the developing nations, osteoporosis is becoming of great concern, in particular among those with increased life expectancy. This is because low trauma fracture can be associated with premature mortality. ${ }^{10,11}$ The prevalence of osteoporosis in the Middle Eastern countries was low as compared with developed 
countries. ${ }^{10}$ It is estimated that $2.9 \%$ bone fractures due to osteoporosis occur in the Eastern Mediterranean. ${ }^{2}$ The occurrence of such fractures is unknown among Jazan women. It has been demonstrated that the occurrence of osteoporosis is for some extent preventable by increased exercise and intake of vitamin D and calcium supplement, reduction of alcohol and smoking. ${ }^{12,13}$ A large body of the evidence demonstrated a connection between healthy behavior and reduced risk of osteoporosis fractures. ${ }^{14}$ It has been shown that knowledge and awareness of osteoporosis and healthy behavior regarding food habits and increased exercise can slow or prevent osteoporosis fractures. ${ }^{15}$ Little information is available online regarding Jazan women's preventative knowledge and behaviors, including physical exercise and type of food, which are good for osteoporosis prevention. Exploring their knowledge and behavior about osteoporosis can help establish preventive health programs for osteoporosis in the region. This study was, therefore, carried out to collect information about knowledge and awareness of osteoporosis among women living in Jazan and describes the type of food habits, sociodemographic characteristics, and other osteoporosis health-related behavior.

\section{MATERIALS AND METHODS}

The study population was estimated as 1,000 women; from these 558 women were randomly selected for the study. These women were health and nonhealth professionals in the age range $\leq 20$ to 50 years. Self-administered questionnaires were randomly distributed to the consenting women from each category. The questionnaires involved 38 questions that investigated the relations of sociodemographic characteristics and the effect of knowledge and awareness of causes and prevention of osteoporosis, in addition, type of food habits and its relation to osteoporosis health. Before the distribution of the questionnaires, the reliability of the constructed questionnaire was successfully tested using sample of women in our college and its teaching clinics and nearby schools.

\section{Measurements}

Gender was assessed as male/female; age was grouped into $\leq 20,21$ to 30,31 to 40 , and $\geq 41$ years. Smoking habits were evaluated as yes/no. In addition, women were asked to respond to the 38-item questionnaire, which was designed for assessments of knowledge of causes of osteoporosis and related health behavior in terms of yes/no/ do not know. Moreover, some parts of the questionnaire contained items assessing food habits, calcium intake, and exercise. The 14-item subscales of susceptibility to osteoporosis, seriousness of osteoporosis, benefits of exercise, benefits of calcium intake, etc. were stated in the form of yes/no/do not know. A sum index of knowledge about osteoporosis per health and nonhealth professionals that range from 1 to 14 was reduced to a dummy variable with high knowledge and low knowledge based on a median split. Using the same response scale, respondents were requested to evaluate 14 knowledge items about osteoporosis per age of the respondents and osteoporosis health-related food habits.

\section{Statistical Analysis}

Data were analyzed using Statistical Software for the Social Sciences version 20.0 (SPSS Institute Inc., Cary, NC, USA). Frequency and percentage were computed for demographic characteristics and other variables, such as age grouping and osteoporosis health-related food habits. Contingency tables were made for different variables.

\section{RESULTS}

The respondents of this study were 548 women: 88 (16.4\%) from health professionals and 458 (83.6\%) nonhealth professionals respectively. The respondents of each category and sociodemographic characteristics are summarized in Table 1. Habits like smoking practiced by study respondents are also shown in Table 1; in this, only $15(3.3 \%)$ are smokers in nonhealth professional women. The numbers and percentage distribution of osteoporosis knowledge items in relation to health professional and nonprofessional are shown in Table 2. Totally, 61.9\% of health professional women scored highly in knowledge of osteoporosis, and regarding nonhealth professionals, totally $54.3 \%$ scored in knowledge items. For instance, 87 (98.9) of health professional responded yes that osteoporosis increases risk of bone fractures and about 423 (92.4) of nonhealth professionals did the same, and when health professional women had been asked if family history predisposes to osteoporosis only small portion, i.e., $20(22.7 \%)$ of them responded by yes; similarly, 115 (25.1\%) of nonhealth professionals responded by yes. To correlate the knowledge of women about osteoporosis and periodontal disease, $48(54.5 \%)$ of health professionals and $174(38.9 \%)$ of nonhealth professionals answered yes. According to age effect, $33.8 \%$ respondents were of young age group and $30.7 \%$ of old age. Table 3 shows the percentage distribution and numbers of the study respondents who confirmed specific causes of osteoporosis according to age groups.

The percentage distribution was $48.1 \%$ of health professionals and $44.2 \%$ of nonprofessionals, regarding osteoporosis behavior and attitude, and calcium and vitamin supplements, in addition to sun exposure. The percentage distribution of health professionals was $50.6 \%$, and $52.6 \%$ was nonhealth professionals, regarding 
Table 1: Percentage distribution and number of study respondents sociodemographic characteristics and habits

\begin{tabular}{lll}
\hline Sociodemographic & $\begin{array}{l}\text { Health professional } \\
\text { participants, } \\
n=88(\%)\end{array}$ & $\begin{array}{l}\text { Nonhealth } \\
\text { professional } \\
\text { participants, } \\
n=458(\%)\end{array}$ \\
\hline $\begin{array}{l}\text { Age (years) } \\
\leq 20\end{array}$ & $0.8(7)$ & $10.3(47)$ \\
$21-30$ & $65.9(58)$ & $43.2(198)$ \\
$31-40$ & $26.1(23)$ & $45.9(210)$ \\
$41-50$ & $0.0(0.0)$ & $1.1(5)$ \\
Marital status & & \\
Married & $54.5(48)$ & $66.8(306)$ \\
Single & $54.5(48)$ & $29.7(136)$ \\
Divorce/widow & $2.3(02)$ & $3.9(18)$ \\
Educational level (years) & & $12.1(55)$ \\
$>10$ & $15.9(14)$ & $87.9(403)$ \\
$<10$ & $84.1(74)$ & $13.9(64)$ \\
Working place & & $51.5(236)$ \\
College & $45.5(40)$ & $34.2(156)$ \\
School & $7.9(7)$ & $0.4(2)$ \\
Hospital & $19.3(17)$ & $3.3(15)$ \\
Others & $27.3(24)$ & $96.7(443)$ \\
Habits & & \\
Smokers & $0.0(0)$ & \\
Nonsmokers & $100(88)$ & \\
\hline & &
\end{tabular}

Table 3: Percentage distribution and number of study respondents who confirmed specific causes of osteoporosis according to age groups

\begin{tabular}{lll}
\hline & $\begin{array}{l}\text { Age group } \\
\leq 30 \text { years } \\
\text { participants, }\end{array}$ & $\begin{array}{l}\text { Age group } \\
\text { participants, } \\
n=311(\%)\end{array}$ \\
$n=237(\%)$
\end{tabular}

Table 2: Percentage distribution and number of study respondents who confirmed specific causes of osteoporosis according to health and nonhealth-related professionals

\begin{tabular}{|c|c|c|}
\hline Osteoporosis knowledge items & $\begin{array}{l}\text { Health } \\
\text { professional } \\
\text { participants, } \\
n=88(\%)\end{array}$ & $\begin{array}{l}\text { Nonhealth } \\
\text { professional } \\
\text { participants, } \\
n=458(\%)\end{array}$ \\
\hline $\begin{array}{l}\text { Osteoporosis increases risk of } \\
\text { bone fractures }\end{array}$ & $98.9(87)$ & $92.4(423)$ \\
\hline Osteoporosis symptoms, e.g., pain & $81.8(72)$ & $76.2(349)$ \\
\hline $\begin{array}{l}\text { Osteoporosis affects periodontal } \\
\text { disease }\end{array}$ & $54.5(48)$ & $38.9(174)$ \\
\hline $\begin{array}{l}\text { Osteoporosis is more common in } \\
\text { men }\end{array}$ & $1.1(1)$ & $2.6(12)$ \\
\hline $\begin{array}{l}\text { Cigarette smoking contributes to } \\
\text { osteoporosis }\end{array}$ & $60.2(53)$ & $53.3(244)$ \\
\hline Osteoporosis is common in women & $89.8(79)$ & $82.3(377)$ \\
\hline $\begin{array}{l}\text { A fall is important in causing } \\
\text { fractures }\end{array}$ & $64.8(57)$ & $84.7(388)$ \\
\hline $\begin{array}{l}\text { Women at } 50 \text { years can develop } \\
\text { osteoporosis }\end{array}$ & $84.1(74)$ & $51.9(238)$ \\
\hline $\begin{array}{l}\text { Physical activity is beneficial for } \\
\text { osteoporosis }\end{array}$ & $53.4(47)$ & $40.8(187)$ \\
\hline $\begin{array}{l}\text { Clinical risk factors tell of risk of } \\
\text { osteoporosis }\end{array}$ & $22.7(20)$ & $25.1(115)$ \\
\hline $\begin{array}{l}\text { Family history predisposes to } \\
\text { osteoporosis }\end{array}$ & $70.5(62)$ & $48.9(224)$ \\
\hline $\begin{array}{l}\text { Osteoporosis is bone loss in } \\
10 \text { years of menopause }\end{array}$ & $84.1(74)$ & $80.6(369)$ \\
\hline $\begin{array}{l}\text { Hormone therapy prevents bone } \\
\text { loss after menopause }\end{array}$ & $62.5(55)$ & $51.7(237)$ \\
\hline $\begin{array}{l}\text { There are no treatments for } \\
\text { osteoporosis available }\end{array}$ & $38.6(34)$ & $31(142)$ \\
\hline
\end{tabular}

osteoporosis prevention food items. In this regard, the scores of respondents for milk intake as good item for osteoporosis prevention were high for both groups: $89.8 \%$ health professionals and $85.8 \%$ nonprofessionals and about the same percentages in relation to sun exposure and osteoporosis prevention. This high knowledge among the respondents may have good implication for feeding policy of their children as a part of the prevention strategy for osteoporosis. The percentages of the respondents who confirmed specific behavior and attitude toward osteoporosis prevention are shown in Table 4.

\section{Ethical Considerations}

Ethical approval was obtained from the Research Office. A written informed consent was obtained from the participants. They were told that knowledge gained from this survey may lead to prevention of osteoporosis and that their information for this research will be confidential and will not be disclosed to others.

\section{DISCUSSION}

Information about osteoporosis knowledge and related health behavior of women in Jazan region has not been 
Table 4: Percentage distribution and numbers of study respondents who confirmed specific behavior and attitude toward osteoporosis prevention

\begin{tabular}{lll}
\hline & $\begin{array}{l}\text { Health } \\
\text { professional }\end{array}$ & $\begin{array}{l}\text { Nonhealth } \\
\text { participants, } \\
\text { participants, } \\
n=88(\%)\end{array}$ \\
$n=458(\%)$ \\
$\begin{array}{l}\text { Osteoporosis behavior professional } \\
\text { and attitude items }\end{array}$ & $33(29)$ & $20.3(93)$ \\
\hline $\begin{array}{l}\text { To prevent osteoporosis, calcium } \\
\text { intake is important }\end{array}$ & & \\
Broccoli is a good source of calcium & $40.9(36)$ & $27.3(125)$ \\
Calcium supplements prevent bone & $15.9(14)$ & $18.6(85)$ \\
loss & & \\
High-impact exercise improves & $45.5(48)$ & $56.8(260)$ \\
bone health & & \\
Osteoporosis prevention food items & & \\
Milk intake is good for osteoporosis & $89.8(79)$ & $85.8(393)$ \\
Yoghurt & $69.3(61)$ & $73.1(335)$ \\
Bread & $13.6(12)$ & $16.8(77)$ \\
Macaroni & $11.4(10)$ & $9.6(44)$ \\
Meat & $26.1(23)$ & $23.1(106)$ \\
Fish & $57.9(51)$ & $65.9(302)$ \\
Egg & $65.9(58)$ & $71.8(329)$ \\
Cheese & $71.6(63)$ & $63.9(293)$ \\
Potatoes & $11.4(10)$ & $12.9(59)$ \\
Vegetables and salads & $64.8(57)$ & $69.4(316)$ \\
Cruciferae (Broccoli, cabbage, & $64.8(57)$ & $68.9(316$ \\
brussels) & & \\
Fruits & $60.2(53)$ & $69.7(319)$ \\
Vitamin supplement & $63.6(56)$ & $56.3(258)$ \\
Sun exposure & $89.9(79)$ & $85.6(392)$ \\
\hline & & \\
& & \\
& &
\end{tabular}

previously published online. This study was, therefore, carried out to collect such information among people to help preventive health program of osteoporosis and its related health behavior. Therefore, women of this study were selected because they were living in Jazan region and in the field of health or nonhealth sectors. In this study, all the categories of women were treated as having equal knowledge in the field of osteoporosis for comparative purposes. Our study indicated that the respondents correctly completed the questionnaire, which indicated their keen interest on osteoporosis matters.

Osteoporosis yields high individual health care costs for treatment, as well as high social costs because of potential dependency and high economic impact. ${ }^{16}$ Studies have indicated that osteoporosis is to a great extent a preventable disease. ${ }^{17}$ However, currently, there is no cure, but there are measures that can prevent or slow the development of the disease. Thus, knowledge and awareness of its related health behavior can influence what actions women should take to prevent osteoporosis. Nursing interventions of osteoporosis have primarily consisted of education to encourage or preventive exercise and healthy nutrition to decrease major risk factors. ${ }^{18}$ Previous research findings on osteoporosis have less focus on knowledge of preventive behavior of young women. ${ }^{19}$
Our study findings show that respondents were highly knowledgeable about osteoporosis and its healthrelated behavior. However, knowledge does not always translate into positive behavior changes without considering other psychological variables that could affect behavior. According to the health belief model used in a variety of studies, healthy behaviors can occur if an individual believes in personal susceptibility to a condition. ${ }^{20}$ Moreover, it has been indicated that in order for health education programs to be successful in changing behavior, the program must match the need of the population. Determining what specific population of women know and believe about osteoporosis can help determine strategy for interventions that will be effective in encouraging preventive health behaviors toward reducing the risk of osteoporosis morbidity and mortality. Our study shows that health professional women were more knowledgeable than nonhealth professionals in that osteoporosis can affect periodontal disease. Evidence indicated that bone loss due to osteoporosis is considered as a risk factor for periodontal bone loss. ${ }^{6}$

This study was conducted by using instruments designed to measure osteoporosis knowledge and related health behavior. Therefore, women in our study were divided into health and nonhealth professionals, because health professionals are closer to public and private health sectors which continuously provide with health information. However, the results of this study show that both groups were equally knowledgeable about osteoporosis and related health behavior. This might be due to the effect of health programs in multimedia. Respondents of this study were also divided into women with younger age and older age. The main objective of the age grouping was to describe the relationship between osteoporosis knowledge and behavior and the effect of age, because increased peak of bone mass loss is usually achieved at the age of 35 years. $^{21}$

The finding of this study demonstrated that the differences of ages have no significant effect on the knowledge of osteoporosis of both groups. This might be because the age range of both groups was so small. Focusing on osteoporosis prevention for young women is consistent with the objectives for health promotion and disease prevention. ${ }^{22}$ In this study, the information gained can provide the basis for developing cost-effective health education programs to prevent osteoporosis among women in this region. Our study findings of osteoporosis knowledge among women of Jazan were also comparable to the findings of other studies. ${ }^{23}$ Despite the cultural differences with other studies, women in our study were highly knowledgeable about osteoporosis preventive food items including milk intake, cheese, fish, and eggs. However, women in our study showed less knowledge 
of exercise as preventive measure of osteoporosis because this specific item in our knowledge measurement might be less relevant to their culture.

\section{CONCLUSION}

This study shows that women of Jazan were highly knowledgeable about osteoporosis and its health-related behavior. Thus, based on our study findings, we recommend the establishment of the preventive education program of osteoporosis that addresses osteoporosis preventive knowledge and related health behavior and that osteoporosis is to a great extent a preventable disease.

\section{ACKNOWLEDGMENTS}

Authors would like to thank the women of Jazan for their participation in this study. The authors also extend their thanks to the interns: Drs Bayan Zurbtan, Salma Swaid, Roaa Tobiagy, for their participation in the distribution of the questionnaires. This study was facilitated by the College of Dentistry, Jazan University, Jazan, Kingdom of Saudi Arabia.

\section{REFERENCES}

1. Arnaud CD. Osteoporosis: Using "bone markers" for diagnosis and monitoring. Geriatrics 1996 Apr;51(4):24-30.

2. Kanis, JA. On behalf of the World Health Organization scientific group: assessment of osteoporosis at the primary health-care level, technical report. UK: WHO Collaborating Centre, University of Sheffield; 2007.

3. Kanis, JA. Osteoporosis: clinical guideline for prevention and treatment. London: Royal College of Physicians; 2000.

4. Kribbs PJ, Smith DE, Chesnut CH 3rd. Oral findings in osteoporosis. Part I: measurement of mandibular bone density. J Prosthet Dent 1983 Oct;50(4):576-579.

5. Geurs NC. Osteoporosis and periodontal disease. Periodontology 20002007 Jun;44(1):29-43.

6. Kribbs PJ, Smith DE, Chesnut $\mathrm{CH}$ 3rd. Oral findings in osteoporosis. Part II: relationship between residual ridge and alveolar bone resorption and generalized skeletal osteopenia. J Prosthet Dent 1983 Nov;50(5):719-724.

7. Klemetti E, Collin HL, Forss H, Markkanen H, Lassila V. Mineral status of skeleton and advanced periodontal disease. J Clin Periodontol 1994 Mar;21(3):184-188.
8. Jordan KM, Cooper C. Epidemiology of osteoporosis. Best Pract Res Clin Rheumatol 2002 Dec;16(5):795-806.

9. Werner P. Knowledge about osteoporosis: assessment, correlates and outcomes. Osteoporos Int 2005 Feb;16(2):115-127.

10. Maalouf G, Gannagé-Yared MH, Ezzedine J, Larijani B, Badawi S, Rached A, Zakroui L, Masri B, Azar E, Saba E, et al. Middle East and North Africa consensus on osteoporosis. J Musculoskelet Neuronal Interact 2007 Apr-Jun;7(2):131-143.

11. Handa R, Ali Kalla A, Maalouf G. Osteoporosis in developing countries. Best Pract Res Clin Rheumatol 2008 Aug;22(4): 693-708.

12. Riggs BL, Melton LJ 3rd. The prevention and treatment of osteoporosis. N Engl J Med 1992 Aug;327(9):620-627.

13. Swaim RA, Barner JC, Brown CM. The relationship of calcium intake and exercise to osteoporosis health beliefs in postmenopausal women. Res Social Adm Pharm 2008 Jun;4(2):153-163.

14. El-Hajj GF, Adib MG, Nauroy L. The Middle East and Africa Regional audit, epidemiology, costs and burden of osteoporosis in 2011. International Osteoporosis Foundation IOF; 2011. Available from: http:/ /www.staff.aub.edu.lb/ webcmop/ downloads/ME_audit.pdf.

15. Troncoso JM. Relationship of osteoporosis knowledge and perceived susceptibility to osteoporosis among Hispanic women. A thesis submitted to Kirkhof School of Nursing, Grand Valley, State University; 2000.

16. Samsioe G. Osteoporosis: an update. Acta Obstet Gynecol Scand 1997 Mar;76(3):189-199.

17. Mayo Foundation for Medical Education and Research. What is Osteoporosis? 2000. Available from: http://www.mayohealth.org/mayo/pted/htm/osteopor.htm.

18. The US Department of Health and Human Services - Public Health Services. Healthy people 2010: National health promotion and disease prevention objectives. (DHHS Publication No. [PHS] 91-50212). Washington (DC): US Government Printing Office; 2000.

19. Sedlak CA, Doheny MO, Jones SL. Osteoporosis prevention in young women. Orthop Nurs 1998 May-Jun;17(3):53-60.

20. Kim KK, Horan ML, Gendler P, Patel MK. Development and evaluation of the osteoporosis health belief scale. Res Nurs Health 1991 Apr;14(2):155-163.

21. Masi L, Bilezikian JP. Osteoporosis: New hope for the future. Int J Fertil Women's Med 1997 Jul-Aug;42(4):245-254.

22. National Osteoporosis Foundation. Clinician's guide to prevention and treatment of osteoporosis. Washington (DC): National Osteoporosis Foundation; 2010.

23. Sayed-Hassan R, Bashour H, Koudsi A. Osteoporosis knowledge and attitudes: a cross-sectional study among female nursing school students in Damascus. Arch Osteoporos 2013 Dec;8(1-2):149. 